\title{
CREATIVE TOURISM AS A NEW PARADIGM IN THE DEVELOPMENT OF CULTURAL TOURISM IN THE REPUBLIC OF MACEDONIA
}

DOI: http://dx.doi.org/10.18509/GBP.2017.21

UDC: $338.48: 7 / 8(497.7)$

\author{
Hristina Dimeska \\ Department of Geography, Faculty of Natural Sciences and Mathematics, Sts. Cyril and \\ Methodius University, Macedonia
}

\begin{abstract}
The culture tourism represents a touristic form that attracts growing number of visitors recurrently. Especially those categories of tourists that have touristic needs and motifs to learn and find out something more about the culture and the cultural heritage of the destination they visit. If there is a possibility of performing additional creative activities included in the visit, then the value of the touristic destination also increases.

The active tourism implies a need of rich cultural heritage for creating an attractive touristic offer, like the one Macedonia has at its disposal. Therefore, in this direction it is very important to use the appropriate available potentials for development of creative tourism.

The paper has a goal to present the basic principles, benefits and potentials which Republic of Macedonia has at its disposal for development of creative tourism. Additionally, this paper will provide a review of the results of a survey in direction of establishing the perspectives that the country features.
\end{abstract}

Key words: Culture tourism, R. Macedonia, creative tourism, perspectives

\section{INTRODUCTION}

Tourism and tourist requirements in contemporary societal flows permanently note changes and imply a creation of new touristic attractions and activities that would satisfy the tourist desires and requirements. Classic, formal forms of tourism are more and more put on the margins, and the primate is taken by new and non-typical forms of tourism. The cultural tourism is such, as well as its forms that slowly but surely become touristic forms that have a high value at the world touristic trade centers and are attractive for tourists. However, the overall touristic development of destinations that is full of traditional cultural touristic attractions and events is not enough in the cultural touristic offer for the last few years. Tourists have started looking for new experiences in the cultural tourism domain. Such novelties are looked for in gastronomy, acquiring some new skills, getting familiar with the tradition and history of the area, learning foreign languages, religion and communication with the domestic citizens. "Tourism is a new form of tourism which has the potential change existing models of tourism development and to make a contribution to diversifying and innovating the tourist experience. By doing so, creative tourism can help to stimulate local economic, social and cultural development" [9]. 
In that direction this paper examines the background and development of the creative tourism concept, showing how the production and consumption of experiences has shifted from cultural tourism to creative tourism.

\section{METHODOLOGY}

When talking about cultural tourism and its activities, it is obvious that we deal with complex phenomena which require application of diverse methods that commonly necessitate a great deal of information. That is why the study is based on classical methodology, which is applied widely in tourism studies, such as research methods of analysis and synthesis which allow us a scientific approach in clarifying the role and place of tourism in national and local economy. That is partially why the survey method was employed in the analysis.

The aim of this paper is, on secondary information, to provide theoretically based case studies analysis of the essential characteristics and key resources of creative tourism in Macedonia and the conditions and factors that determine its development and on the basis of primary information to develop a framework that can act as a policy and guide for further planning of this type of tourism in general.

\section{THEORETICAL ASPECTS AND DEVELOPMENT OF CREATIVE TOURISM}

Creative tourism was first defined by Richards and Raymond "as an extension or a reaction to cultural tourism. According to them creative tourism is tourism which offers visitors the opportunity to develop their creative potential through active participation in learning experiences which are characteristic of the holiday destination where they are undertaken" [5]. UNESCO then defines creative tourism as with participative learning in the arts, heritage, or special character of a place, and it provides a connection with those who reside in this place and create this living culture [11]. "Distinctions between tourism, recreation and leisure are slowly fading in the postmodern world. It is difficult to differentiate between tourists and participants in other forms of recreation. Tourism and recreation offerings take place in the same facilities and compete for customers' use of money and time" [1]. "This need of learning can be focused on versatile local activities, enabling the use of local skills. This not only generates revenue in the host communities but also offers meaningful contact between hosts and guests" [6]. Smith discusses the increasing importance of creativity in the development of cities and destinations. According to her, traditional heritage sites as such will not be enough in today's keen competition. Furthermore, the destination may not even have enough heritage attractions to promote but need to shift focus on developing contemporary tourism products based on the idea of creative tourism [10].

Richards and Wilson highlight the role of lifestyle entrepreneurs, who tend to choose rural settings with established creative communities for their operations [9]. The creative and imaginative capital of the respective locations tends to pave the way for successful tourism businesses. Richards sees as the main drivers of creative tourism the standardized nature of products on the one hand and modern man's need for self development on the other hand [6]. From a destination point of view the cons of creative tourism are obvious: the meaningful contact between hosts and guests can be transformed into economic gain as locals are needed to teach the tourists whatever local skills they are eager to pursue. This way the leakages of the local economy can be cut off. To do this successfully, Richards emphasizes that on the destination level it is of utmost importance to find the linkage between the resources of the destination and the needs of the tourists [6]. Only 
this combination can successfully bridge the supply and the demand.

Creativity and the outcome of creative processes, innovation, require the right environment and sufficient time resources. Furthermore, ability to co-operate and communicate is a prerequisite for creativity. "Creative tourism should provide a valuable experience for tourists and transfer unique values promoting local identities. Moreover, creative tourism is a projection of a new tourism type in which natural, cultural and personal resources are not manipulated and exploited but valued and enriched" [2].

\section{THE MEANING OF CREATIVE TOURISM AS A CONCEPT AND TRANSITION FROM CULTURAL TOWARDS CREATIVE TOURISM}

Creative tourism is generally perceived as a form of cultural tourism and it is essentially different from the mainstream cultural tourism as it will be elaborated further in the paper. While traditional cultural tourism is based on "viewing", "seeing" and "contemplating" (e.g. visiting museums, art galleries, concerts, ballet performances and the like), creative tourism is based on "experiencing", "participating" and "learning" [4]. This is how creative tourism is positioned as a part of the next generation of such tourism, which has a target of satisfying the self-actualization need, mostly concentrating on development of active skills. Moreover, creative tourism includes tourist resources that are actually essentially processes (ex. Crafts, festivals, singing, dances, painting etc.), and it is precisely this that makes it not so bound to locations compared to cultural tourism in general.

"Creative tourism is, therefore, more sustainable in nature than traditional cultural tourism based on the consumption of built environments and contributes to the development of the destination" [9]. Therefore, the increased meaning and the more intensive development of this selective form of tourism is not only caused by the fullness of tourists from the forms of cultural tourism up until now, and as products that are only offered on the market, but also from the wish of tourists to be interacting with the destination and its cultural heritage. According to Richards, the creative tourism is driven by a few factors from the sphere of production and consumption: skilled nature of consumption, growing importance of experiences, and greater role for intangible and everyday culture in tourism [8]. The basic characteristics of these factors will be explained in continuance:

The rise of skilled consumption - Society nowadays is largely moving towards something called "skilled consumption", in education inclusion, self-development and creative activities in general that depend on individual capability and creativity, whereby unskilled consumption has a tendency of being boring and repetitive. In this sense, skilled consumption is becoming more interesting in the process of practice itself. The increase of the challenge level, and consequently the excitement, is all coming from exercising the activity and skill development.

The experience economy - "The Experience Economy means competition that has goods production or services as a foundation, and those are replaced by competition for experiences production. What they argue is that goods and services can be simply copied, which in turn decreases the prices resulting in profit reduction. Contrary, experiences are actually unique phenomena hard to be copied since they are produced for consumers, also directly involving them individually" [4].

Shift from tangible to intangible tourism resources - The increasing deployment of intangible cultural resources in the tourism product increases the experiences' importance. Tourism becomes more and more dependent on intangible elements like for 
example the image and the area environment. The media is becoming growingly important for creation and distribution of such images. What is also significant are the narratives, which create 'stories' about people and locations which is what makes certain destinations attractive.
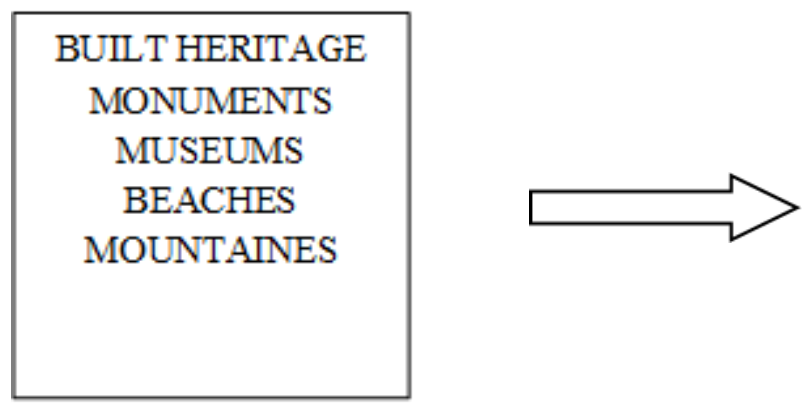
IMAGE
ATMOSPHERE
IDENTITY
LIFESTYLES
NARRATIVES
CREATIVITY
MEDIA

Figure 1. The shift from tangible to intangible resources in tourism [7]

Shift from high culture to everyday culture - The increasing significance of intangible culture also means that the cultural content type is changing. Previously, cultural tourism was actually dominated by high culture, meaning the museums, art galleries, monuments and similar venues, which are what constitutes the 'must-see' sites for numerous destinations. These mass sites actually become increasingly avoided for the typical tourist nowadays, whose desire is to look for small-scale, non-typical touristic places which other tourists haven't yet discovered. Local places like bars, cafes and restaurants that serve local food, which the locals also consume, the markets which sell fresh products from the region, all of these are types of places where tourists hope to find 'authentic' culture.

Desire for active, engaging experiences - The tourist has a desire to have more direct contact with real people and engaging with local culture and creative practices. The postmodern identity search including the roots and the meaning inspires number of people to look for experiences that provide them the chance to have interaction with the local communities, finding out more about them and their relation to the world.

The need for places to make themselves more distinctive - Simultaneously with tourist' search for new experiences, the number of transforming places also increases. The issue becomes the question on how to make it stand out from the crowd. Of course, some cities have exercised the method of building new monuments, just to appear on global stage, like Guggenheim in Bilbao, Spain. However, the places that are able to afford this type of investments are not too many. Utilization of creative resources in development of intangible events and attractions may represent a good alternative for a number of communities. For example, the celebration of the Orthodox Christian holiday Vodici in Ohrid, where the visitors have a chance to be included in the celebration.

The analyzed changes in producing and consuming of tourist experiences brings us to the conclusion that there is a double shift happening in the foundation of cultural tourism. Looking at the consumers, they are more actively included in the culture, and the producers are starting to use the whole potential of cultural and creative resources, that they have available and incorporate the lifestyle culture since this is what makes the destination distinguishable from others.

When the creative tourism is analyzed, many essential characteristics stand out as a segment of cultural tourism, such as:

- increased touristic value of the destination thanks to the creativity; 
- includes utilization of non-material values that thanks to creative tourism can be used, differing from the material values that are prone to degradation and various physical damages;

- Relatively easy promotion and decreased need for infrastructural elements when distributing the final touristic product;

- Distinct economic development;

- Preservation and protection of spiritual and sacral values, which are a form of cultural heritage.

\section{CREATIVE TOURISM AND TOURISTIC DESTINATION}

In the concept and development of creative touristic destinations, the management has a significant role, having a challenge to create an offer that will be unique and authentic for the tourists, at the same time not disturbing the destination's identity and not disrupting the cultural resources and the life of the local community.

"Creative Tourism" involves more interaction, in which the visitor has an educational, emotional, social, and participative interaction with the place, its living culture, and the people who live there. They feel like a citizen. This third generation requires that managers also evolve, recognizing the creativity within their city as a resource, and providing new opportunities to meet the evolving interests of tourists. "Creative Tourism" is considered to be a new generation of tourism. "The development of creative touristic destination should be happening through a process of interaction among the visitors and the destination, at the same time living an experience that is enabled by the offered creative "treasure" [11]. In this direction, the development of touristic destination imposes the need of active participation of tourists in the role of co-creators of the cultural experience that they will gain from the destination. This simplifies the process of the destination's sale as a ready touristic offer or a service. This way, the process of preservation of the destinations' identity will become easier, as well as the stimulation of the consumption of the local culture and its creative output.

On the world's tourism market, famous cultural destinations increasingly develop different types of creative tourism like for example Barcelona, the program Creative Austria in Austria, Ontario in Canada etc. Less known cultural destinations also have their own offer directed towards creative tourists and offer different activities for development of creative tourism and use this to increase the destination's competitiveness. Possibilities for development of creative tourism can be seen in the following facts:

- Creative tourism is not the only possible development option of the cultural tourism of the destination, but a specific part of the offer;

-In developing creative tourism, the creativity is quite important in creating the touristic supply of the destination;

-It can be developed in destination that desires to strengthen its position among destinations that have cultural tourism as a development concept;

-It can be developed into a destination that wants to strengthen its position among destinations that chose cultural tourism as a development concept;

-Creative tourism must be developed in such a way to preserve the values of the cultural resources and the quality of life of the local community;

-Creative tourism can be developed by a destination that does not possess sufficient cultural resources, but develops or wants to develop cultural tourism;

-Creative tourism builds on the existing touristic products of the destination and builds a unique image of the creative destination; 
It is possible to develop creative tourism inside of different social phenomena, creative activities and programs like for example organizing different culinary workshops, art colonies, studying traditional customs, dances, singing and playing instruments, writing abeceda, old fashioned fishing, etc.

These different types of creative experiences are also linked to various forms of delivery and organization structure. Many new networks are springing up which link together creative producers in order to engage in collaborative marketing and to increase the visibility of creative activities. Destinations are also beginning to form partnerships of creative enterprises, as well as linking the creative and tourism sectors in order to develop new creative experiences.

\section{CREATIVE TOURISM DEVELOPMENT POSSIBILITIES IN THE REPUBLIC OF MACEDONIA}

Republic of Macedonia is known by the significant cultural heritage, connected with ethnographical and ethnological characteristics, and numerous events that are created on different basis. However, still Macedonia has huge cultural potential at its disposal, that can be a great pre-condition for development of cultural, and consequently, creative tourism, and for a long time is accounted for a destination directed towards the summer season.

The creative tourism as one segment in the complexity of the cultural tourism can contribute in the creation of a special cultural touristic offer, but also in strengthening of the competitive position of the Macedonian destination in the development of cultural tourism. The claims in direction of the actual touristic trends listed in the national strategy for tourism, that foresee a change in the behavior of the tourists in searching new and authentic experiences also take part in the context of the development of cultural tourism. The demand of the so-called "sunny vacations" will stagnate, even decrease, and the travels based on activities will increase, and there will be a shortening of the long vacations in favor of more short ones, and the cities will have benefit.

The prognosis point to alternative means to spend the resources, time and financial means and the more experienced tourist will more often show interest in larger environment authenticity, especially in the direction of emotional satisfaction and the need for personalization.

The creative tourism and the necessity for its development as evolution in the offer of cultural tourism in the Republic of Macedonia are exceptionally important. However, still in this country there is no national strategy for development of cultural tourism, at all. This type of tourism development should be given a special importance in the appropriate documents, because of the content, the organizational and the social advantages it offers. Creative tourism can occur as an additional value in the destinations, or as a new initiative in those destinations that are only now shaping and breaching on the tourist market. In the touristic offer of Republic of Macedonia, creative tourism does not exist as an organized and independent offer, but a large number of workshops and events that are creative by their nature can be found, and these enrich the touristic package offered to the visitors. Such are a large number of art colonies, visits of sheepfolds where the visitors are included in the process of making the cheese, taking part in preparation of local food specialties, production of wine and rakija, taking part in different crafts etc.

In addition, the results by survey done with tourists in one of the most meaningful cultural-historical monuments in Skopje but also in Macedonia are given. The survey was conducted in February, 2017 and was done over a representative group made by domestic 
and foreign tourists. Concerning the condition with the creative tourism in Macedonia, the results are surprising, which say that high $60 \%$ of the tourists would actively take part in certain activities, out of which the biggest percentage belongs to gastronomic activities, then comes the archeological sites, craftsman workshops and manifestations. Out of which the highest percent belongs to the gastronomic activities with $21.6 \%$, the participation in craftsman workshops follows with 18,3\%, while in archeological cites $16,6 \%$ of the examinees wanted to be included and in agricultural activities $15 \%$. Of those which chose to participate in craftsman workshops $72 \%$ are women, while regarding the archeological sites $63 \%$ were male. The education degree suggests active participation in touristic movements connected to cultural tourism with examinees with university or higher degrees. Of the survey respondents 53\% finished university education, $11 \%$ are Masters of Science, while 6\% had PhD degrees. As a primary goal for visiting the Old bazaar in Skopje, $40 \%$ of the respondents list the religious buildings, represented with churches, monasteries and mosques, $20 \%$ listed the cultural manifestations, while the museums and the atmosphere had equal number of respondents, namely $13 \%$.

The data shown indicate the need of including the creative activities in the touristic tours and arrangements, intended for the domestic, but also the foreign tourists. These type of activities would cause numerous positive consequences:

- Development of certain touristic destinations that are not sufficiently or not at all included in the touristic offer;

- Strengthening the small and medium enterprises;

- Negligible investments;

- Creative programs that have influence over the competitiveness of the tourism product;

- The spending in the destination increases;

- Decrease of the seasonality (a problem that affects all touristic destinations in the country, including Skopje, although in the capital seasonality in tourism is the least expressed);

- Preservation of the cultural heritage.

\section{CONCLUSION}

Undoubtedly, the creative tourism is one of the newer and current touristic forms that are especially attractive for a growing number of tourists, including those groups that chose Republic of Macedonia as a touristic destination. In this direction we need to use the numerous potentials that we as a country have at disposal and to transform them into creative activities, which will keep the attention of a large number of tourists.

Creative tourism opens up a space for numerous benefits and as it can be noted by the conducted survey results, needs to be used in the right direction. Moreover, it is necessary to direct the tourism towards preparation of specific strategic programs and plans for development of cultural tourism in the country at national or regional level, and to then approach to a more serious and responsible plan in the development of creative tourism, which will of course lead to numerous positive results. 


\section{REFERENCES:}

[1] Cooper, C., Fletcher, J., Fyall, A., Gilbert, D. \& Wanhill, S., Tourism Principles and Practice. Harlow: Pearson Education Limited, UK, 2005;

[2] Jelinčić, D. A., \& Žuvela, A., Facing the Challenge. Creative Tourism in Croatia, Journal of Tourism Consumption and Practice, 4 (2), pp78-90, 2012

[3] National Tourism development Strategy 2009-2013, Government of the Republic of Macedonia, Skopje, 2009;

[4] Pine, B.J. \& Gilmore, J.H., The Experience Economy, Boston: Harvard University Press, Boston, MA, 1999;

[5] Richards, G. \& Raymond, C., Creative Tourism. In Atlas News no. 23, pp 16-20, 2000;

[6] Richards, G., Creativity: A new strategic resource for tourism? In Tourism, creativity and development. ATLAS Reflections 2005, Association for Tourism and leisure Education, Netherlands, 2005;

[7] Richards, G., Creative tourism and local development. In: Wurzburger, R., Pattakos, A. and Pratt, S. (eds) Creative Tourism: A global conversation. Santa Fe: Sunstone Press, USA, 2009, pp. 78-90;

[8] Richards, G., The Impact of Culture on Tourism. Paris: OECD, 2009;

[9] Richards, G. \& Wilson, J., Developing Creativity in Tourist Experiences: A Solution to the Serial Reproduction of Culture. Tourism Management, 27(6), pp. 1209-1223, 2006; [10] Smith, M., Tourism, culture and regeneration: differentiation through creativity. In Tourism, creativity and development, ATLAS reflections 2005, Association for Tourism and leisure Education, Netherlands, 2005;

[11] UNESCO Creative Cities Network. (2006). Towards Sustainable Strategies of Creative Tourism: Discussion Report of the Planning Meeting for 2008 International Conference on Creative Tourism Santa Fe, New Mexico, U.S.A. October 25-27, 2006. Retrieved from: http://portal.unesco. org/culture/fr/files/34633/118 48588553oct2006 meetingreport.pdf/oct2006meetingreport.pdf 